\title{
Copper Nanoparticles and Antioxidant Stress: Problem Makers or Solvers?
}

\author{
Michael AB Naafs* \\ Dutch Internist Endocrinologist, Netherlands \\ *Corresponding author: Michael AB Naafs, Dutch Internist Endocrinologist, Netherlands \\ Submission: January 23, 2019; Published: January 28, 2019
}

\begin{abstract}
In this mini-review various aspects of copper nanoparticles are considered with a special emphasis on antioxidant stress. Copper nanoparticles may become a problem maker for the environment but seems a problem solver in wound dressings and potentially in diabetes and cancer. Longterm toxicity of copper nanoparticles is not known. An international registry agency should control the use of copper nanoparticles, especially in food nanotechnology.
\end{abstract}

\section{Introduction}

The increased use of metal nanoparticles in the food chain is an increasing concern. Nanoparticles (NPs) are used in various areas, including medicine, electronics, cosmetics, oil lubricants and also in the food chain. The extensive use of these NPs allows them to be released into the environment either during production use or disposal. Phytotoxicity of copper NPs has already been reported [1]. Copper NPs are believed to cause oxidative stress by increasing the activity of oxidative stress enzymes as catalase, superoxide dismutase and glutathion-S-transferase [1,2]. Copper NPs cause in this way a dose dependent toxicity via inducing reactive oxygen species (ROS) and nitrous oxide (NO) [3]. Toxicity of copper NPs has been studied mainly in animals and is manifested as hepatoand renal toxicity, splenic toxicity, neurotoxicity ,gene toxicity and carcinogenicity at LD 50 values of nano- copper $(23.5 \mathrm{~nm})$ of $413 \mathrm{mg} / \mathrm{kg} /$ body/weight [4]. Copper $(\mathrm{Cu})$ is a redox active metal and an essential nutrient in all species. Deficits and excessive amounts can result in human disease and oxidative stress plays a major role in both circumstances. Copper deficiency can contribute to the development and progression of cardiovascular disease and diabetes [5]. Copper NPs showed antidiabetic and antioxidant properties [6]. In addition, copper NPs are used as antibacterial and antifungal agents [7]. So, are copper NPs problem makers or problem solvers? In this mini-review the various aspects of copper NPs will be discussed.

\section{Synthesis}

Copper NPs are very attractive due to their high thermal conductivity and relatively low costs compared to e.g. gold and silver nanoparticles. They can be synthesized by physical, chemical and green techniques. Vacuum vapor deposition, pulsed laser ablation, pulsed wire discharge and mechanical wiring are physical techniques Chemical reduction ,microemulsion techniques, sonochemical reduction, electrochemical, microwave assisted and hydrothermal are chemical approaches for the synthesis of copper nanoparticles [4,5,8]. Green synthesis of copper NPs is using different plants, bacteria and fungi $[9,10]$.

\section{Characteristics}

The properties of copper NPs depend largely on size, structure, shape ,surface properties, particle aggregation, agglomeration and optical characteristics. Their catalytic activity increases with the decrease in size of copper NPs [11].

\section{Catalytic activity}

Catalysts are substances that promote and accelerate chemical reactions without being consumed. Catalysis based on copper NPs may benefit for example the synthesis of methanol or the production of hydrogen on an industrial scale [11-13].

\section{Antibacterial/Antifungal action}

It has been known for a long time that copper and copper alloys have antimicrobial properties [14]. Copper has two key properties that are exploited in consumer products and medical devices. Copper has potent biocidal properties and is critical for most tissues including the skin. In the skin, copper is involved in the synthesis and stabilization of extracellular matrix skin proteins and angiogenesis [14]. It is therefore not surprising these properties are leveraged of copper-oxide NPs impregnated wound dressings [14-17].

Copper has antimicrobial activities against Gram-positive and Gram-negative bacteria, including methicillin-resistant Staphylococcus aureus (MRSA), Clostridium difficile, vancomycin- 
resistant enterococci (VRE) and ESBL-producing species as well as adenoviruses, Influenza A and fungi $[14,18]$.

\section{Cytotoxicity}

Elevated copper levels result in the loss of membrane integrity, which causes essential nutrients, including potassium and glutamate to leak from cells and cause apoptosis [14]. Shafagh et al. [19] studied cytotoxicity and apoptosis of copper oxide NPs on a chronic myeloid leukemia (CML) K562 cell line. CuO NPs showed selectivity towards the K562 cell line and are potentially a good anti-cancer drug since it does not kill healthy cells. Apoptosis is mediated through reactive oxygen species (ROS) production in cancer cells, starting with P53 up-regulation [19]. Copper NPs also induced apoptosis in a human skin melanoma cell line [20]. Similar findings have been reported in a glial cancer cell line by Kukia et al. [21].

\section{Antioxidant activity}

Copper oxide (CuO) NPs have higher toxic effects than $\mathrm{Cu}$ NPs due to its oxidative property. $\mathrm{CuO}$ NPs stimulate photosynthesis at low concentrations $(<0.25 \mathrm{mg} / \mathrm{L})$ but suppression of photosynthesis was observed at $1 \mathrm{mg} / \mathrm{L}$ concentration. CuO NPs have been shown to enhance the production of reactive oxygen species (ROS). At low copper concentrations these ROS' are protective in plants, but at high $\mathrm{Cu}$ concentrations they may be cytotoxic and lead to apoptosis, as mentioned before [4,22]. In addition, phytohormones were also observed to be altered as a response to CuO NPs [23]. Most studies of the antioxidant effects of $\mathrm{Cu}$ NPs have been done in animals [4]. The effect of antioxidant stress on cytochrome P450 and liver disease has been studied in rats and in cancer cell lines $[24,25]$. In humans, curcumin Cu NPs have been studied mostly for their potential anti-cancer activity [26,27]. Although curcumin has been strongly advocated as a natural antioxidant in vitro, in vivo and clinical studies are not able to provide evidence for a significant role in the prevention of cancer. Even with modern curcumin nanoformulations poor curcumin bioavailability could not be overcome [28].

\section{Metabolic disease}

Nanotechnology has been used in diagnosing and monitoring of diabetes by sensor technology [29,30]. Ghosh et al. [6] suggested an antidiabetic effect of copper NPs by inhibiting the enzyme alpha-glucosidase. Javed et al. [31] believe that copper NPs can have hypoglycemic properties. Recently, it has been reported that patients with metabolic syndrome need more vitamin $C$ to break the cycle of antioxidant depletion [32]. It is very well possible that the antidiabetic effects of copper NPs are achieved by restoring vitamin $\mathrm{C}$ mediated antioxidant depletion in the metabolic syndrome. Therefore, it is interesting to know that CU NPs can be prepared with ascorbic acid (vitamin $\mathrm{C}$ ) by an aquous solution reduction method [33]. It has also been known that vitamin $\mathrm{C}$ depletion lowers the uptake of copper [34].

\section{Conclusion}

It is obvious that the widespread use of copper NPs in all kind of sectors can lead to large environmental problems. The use of these NPs has not been regulated and toxicity is not known for the long term. Accumulation in the environment has clear toxic effects on plants when these NPs are used in pesticides and fertilizers. Detection of $\mathrm{Cu}$ NPs in the environment is extremely difficult [35] and therefore copper NPs could be problem makers in the long term. Long-term toxicity in humans is not known and an international registry agency covering the use of NPs and Cu NPs should be instituted therefore, especially for food nanotechnology [28]. On the other hand, the use of Cu NPs in wound dressing and diabetes sensor technology ,as well as their antimicrobial spectrum are of proven benefit [14-18,30]. So, they are problem solvers, too. The anti-cancer activity still has a potential future in nanomedicine and has been explored not enough, yet. So, there has to be done still much more research in the ecological effects of NPs, in nanomedicine and especially in food nanotechnology..

\section{References}

1. Mosa KA, El-Naggar M, Ramamoorthy K, Alawadhi H, Elnaggar A, et al. (2018) Copper nanoparticles induced genotoxicity, oxidative stress, and changes in superoxide dismutase (SOD) gene expression in cucumber (Cucumis sativus) plants. Front Plant Sci 9: 872.

2. Gupta YR, Sellegoander D, Kannan M, Deepa S, Senthilkumaran B, et al. (2016) Effect of copper nanoparticles exposure in the physiology of the common carp (Cyprinus carpio): Biochemical, histological and proteomic approaches. Aquaculture \& Fisheries 1: 15-23.

3. Baeg E, Sooklert K, Sereenaspun A (2018) Copper-oxide nanoparticles cause a dose-dependent toxicity via inducing reactive oxygen species in drosophila. Nanomaterials 8(10): 824 .

4. Hejazy M, Koohi MK, Pour AB (2018) Toxicity of manufactured copper nanoparticles: A review. Nanomed Res J 3(1): 1-9.

5. Adams JU, Keen CL (2005) Copper, oxidative stress and human health. Mol Aspects Med 26(4-5): 268-298.

6. Ghosh S, More P, Nitnavare R (2015) Antidiabetic and antioxidant properties of copper nanoparticles synthesized by medical plant dioscorea bulbifera. J Nanomed Nanotechnol S6: 007.

7. Mahmoodi Elmi A, Nezhadi H (2018) Copper nanoparticles as antibacterial agents. J Mol Pharm Org Process Res 6: 140.

8. Jain S, Nagar N, Devra V (2015) Synthesis and characterization of highly efficient copper nanoparticles and their catalytic application in oxidative kinetic study. Adv Appl Sci Res 6(6): 171-180.

9. Rafique M, Rasheed R, Shaikh AJ (2017) A Review on Synthesis, Characterization and Applications of Copper Nanoparticles Using Green Method. Nano Brief Rep Rev 12(4).

10. Nagar N, Devra V (2018) Green synthesis and characterization of copper nanoparticles using Azadirachta indica leaves. Mat Chem \& Phys 213: 44-51.

11. Jain S, Jain A, Kachhawan P, Devra V (2015) Synthesis and size control of copper nanoparticles and their catalytic application. Transactions Non Ferr Met Soc China 25(12): 3395-4000.

12. Zhang Y, Wang K, Zheng N, Zhang S, Wu J (2013) Effect of copper nanoparticles dispersion on catalytic performance of $\mathrm{Cu} / \mathrm{SiO}_{2}$ catalyst for hydrogenation of dimethyl oxalate to ethylene glycol. J Nanomaterials 7: 1-6.

13. Gondwal M, Pant GJ (2018) Synthesis and catalytic and biological activities of silver and copper nanoparticles using Cassia occidentalis. Int J Biomat, pp. 1-10.

14. Naafs MA (2017) Antimicrobial properties of copper and copper alloys for infection control. Infection Control tips. 
15. Ovarzun Ampuera F, Vidal A, Concha M, Morales J, Orellana S, et al. (2015) Nanoparticles for the Treatment of Wounds. Curr Pharm Des 21(29): 4329-4341.

16. Kalashnikova I, Seal S, Das S (2015) Nanomaterials for wound healing; scope and advancement. Nanomedicine 10(16): 2593-2612.

17. Berkow G, Galbay J, Dordik R, Eidelman AI, Lavie Y, et al. (2010) Molecular mechanisms of enhanced wound healing by copper oxide impregnated dressings. Wound Repair Regen 18(2): 266-275.

18. Meyer TJ, Ranfall J, Thu P (2015) Antimicrobial properties of copper in gram -negative and gram-positive bacteria. Int J Biomol Agric Food and Biotechnol Engineering 89(3).

19. Shafagh M, Rahmani F, Delirezh N (2015) CuO nanoparticles induce cytotoxicity and apoptosis in human K562 cancer cell line via mitochondrial pathway, through reactive oxygen species and P53. Iran J Basic Med Sci 18(10): 993-1000.

20. Chakraborty R, Basu T (2017) Metallic copper nanoparticles induce apoptosis in a human skin melanoma A375 cell line. Nanotechnology 28(10): 105101.

21. Kukia N, Abbasi A, Froushani S (2018) Copper oxide nanoparticles stimulate cytotoxicity and apoptosis in glial cancer cell line. Dhaka Univ J Pharm Sci 17(1): 105-111.

22. Rastog A , Zivcak M, Sytar O, Kalaji HM, He X, et al. (2017) Impact of Metal and Metal Oxide Nanoparticles on Plant: A Critical Review. Front Chem 5: 78.

23. Nair R () Effects of nanoparticles on plant growth and development. In: Kole C, Kumar DS, Khodukovskaya MV (Eds.), Plant Nanotechnology, Cham: Springer, Switzerland, pp. 95-118.

24. Tang H, Xu M, Shi F, Ye G, Lv C, et al. (2018) Effects and mechanisms of nano-copper exposure on hepatic cytochrome P450 enzymes in rats. Int J Mol Sci 19(7): 2140.

25. Rehana D, Muhendiran D, Kumar RS, Rahiman AK (2017) Evaluation of antioxidant and anticancer activity of copper oxide nanoparticles synthesized using medicinally important plant extracts. Biomed Pharmacother 89: 1067-1077.

26. Kamble S, Utage B, Mogle P, Kamble R, Hese S, et al. (2016) Evaluation of curcumin capped copper nanoparticles as possible inhibitors of human breast cancer cells and angiogenesis: A comparitive study with native curcumin. AAPS Pharm Sci Tech 17(5): 1030-1041.

27. Greish K, Pittala V, Taurin S, Taha S, Bahman F, et al. (2018) curcumincopper complex nanoparticles for the management of triple negative breast cancer. Nanomaterials 8(11): 884.

28. Naafs MA (2018) Curcumin and Food Nanotechnology. CPQ Medicine 3(6): 01-10.

29. Veiseh O, Tang BC, Whitehead KA, Anderson DG, Langer R (2015) Managing diabetes with nanomedicine: challenges and opportunities. Nat Rev Drug Disc 14(1): 45-57.

30. Naafs MA (2018) Sensor technology developments in diabetes monitoring. CPQ Medicine 2(1): 01-14.

31. Javed R, Ahmed M, Haq IU, et al. (2017) PVP and PEG doped CuO nanoparticles are more biologically active: Antibacterial, antioxidant and diabetic and cytotoxic perspective. Mater Sci Eng C Mater Biol Appl 79: 108-115.

32. Maret G, Traber GR, Bruno RS (2018) Relationship between vitamin c status, the gut-liver axis and metabolic syndrome. Redox Biology 21: 101091.

33. Liu Q Yasunami T, Kuruda K, Okido M (2012) Preparation of $\mathrm{Cu}$ nanoparticles with ascorbic acid by aquous solution method. Transact. Non Ferr Met Soc China 22(9): 2198-2203.

34. Gaethe LM, Chow CK (2003) Copper toxicity, oxidative stress and antioxidant nutrients. Toxicology 189(1-2): 147-183.

35. Navratilova J, Praetorius A, Gondikas A, Fabienke W, Vonder Kammer F, et al. (2015) Detection of engineered copper nanoparticles in soil using single particle ICP MS. Int J Environ Res Public Health 12(12): 1575615768.

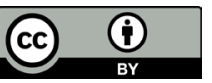

Creative Commons Attribution 4.0 International License

For possible submissions Click Here

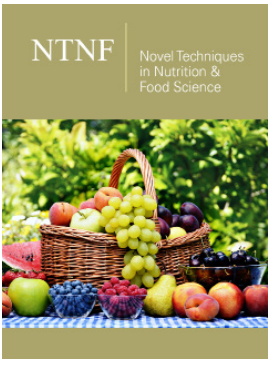

Novel Techniques in Nutrition and Food Science

\section{Benefits of Publishing with us}

- High-level peer review and editorial services

- Freely accessible online immediately upon publication

- Authors retain the copyright to their work

- Licensing it under a Creative Commons license

- Visibility through different online platforms 